\title{
Hypoxic-ischemic encephalopathy in a young man due to tramadol overdose
}

\author{
Zahra Ataee*, Bita Dadpour
}

Medical Toxicology Research Center, Faculty of Medicine, Mashhad University of Medical Sciences, Mashhad, Iran

\author{
Received: 23 September 2019 \\ Accepted: 27 November 2019 \\ Published online: 6 December \\ 2019 \\ *Corresponding author: Zahra \\ Ataee,edical Toxicology Research \\ Center, Mashhad University of \\ Medical Sciences. \\ Email: ataeez@mums.ac.ir \\ Competing interests: None. \\ Funding information: None. \\ Citation: Ataee Z, Dadpour B. \\ Hypoxic-ischemic encephalopathy \\ in a young man due to tramadol \\ overdose. Journal of Emergency \\ Practice and Trauma 2020; 6(2): 112 \\ 114. doi: 10.34172/jept.2019.21.
}

\begin{abstract}
Objective: Tramadol is a synthetic analgesic with two mechanisms. The opioid and non-opioid mechanisms are responsible for tramadol side effects. Non-opioid side effects of tramadol are due to the reuptake inhibitions of serotonin and norepinephrine. Some of the side effects include anaphylactoid reactions, CNS depression, hypoglycemia, hypotension, respiratory depression, seizures, and serotonin syndrome. Seizure may happen in therapeutic doses. If the frequency of tramadol seizures increases, ischemic brain injury and hypoxic-ischemic encephalopathy can be induced.

Case Report: We report a young man with a history of tramadol abuse that was admitted with status epilepticus in Imam Reza hospital in Mashhad, Iran. Due to his altered mental status, he was intubated and antiepileptic agents were prescribed. He was transferred to ICU. After regaining consciousness, he was extubated and with the prescription of rehabilitation support he was discharged.

Conclusion: Tramadol is a synthetic analgesic agent with less potential for dependence. It is important to mention that the overdose of this drug is common. This drug has two mechanisms. This paper reports a case that developed generalized tonic clonic seizures due to tramadol and hypoxic ischemic encephalopathy. With adequate treatment and supportive care, patient's mental status improves and he/she can be discharged.

Keywords: Tramadol, Status epilepticus, Hypoxic ischemic encephalopathy, Antiepileptic
\end{abstract}

\section{Introduction}

Tramadol is a synthetic analgesic agent that is used for moderate to relatively severe pain with neuropathic and nociceptive mechanisms like renal colic (1). Tramadol has two mechanisms namely opioid and non-opioid mechanisms. The opioid mechanism is like other opioids and binds to $\mu$-opiate receptors and suppresses the perception of pain (2). On the other hand, nonopioid mechanism is the inhibitor of serotonin and norepinephrine reuptake (3). Anaphylactoid reactions, CNS depression, hypoglycemia (4), hypotension, respiratory depression, seizures, and serotonin syndrome are the most important side effects of tramadol (5). Evidence shows that seizures of tramadol happen on the first day of use (6) and they are not cured by naloxone, but they are suppressed by benzodiazepines.

Animal research studies show that the inhibition of gama aminobutyric acid receptors may induce the severity of tramadol seizures $(7,8)$. Seizure of tramadol may happen in therapeutic doses especially with the use of alcohol, tricyclic anti-depressant, selective serotonin reuptake inhibitor, serotonin-norepinephrine reuptake inhibitor, anorectics, other opioids, neuroleptics, monoamine oxidase inhibitor inhibitors, and drugs which may lower seizure threshold.

In recent years, the abuse of tramadol is on the rise and it is one of the drugs to be searched on the net (9). In recent years the prevalence of tramadol overdose in Iran has increased (10-12). The seizure risk in tramadol overdose is about $15 \%-35 \%(10,13)$. Status generalized tonic-clonic seizures produce sever ischemia in brain and brain stem as well as medulla which can lead to hypoxic ischemic encephalopathy. Severity and duration of hypoxia and the neurologic past medical history can determine a patient's prognosis (14). In this paper we review the effects of tramadol seizure in a young patient.

\section{Case Report}

A 21-year old man was referred to the emergency due to frequent seizures and decreased level of consciences. He had overdosed some tramadol oral tablets and was referred to emergency department with recurrent tonic clonic seizures and decreased consciousness. The information obtained from the patient concerning drug history, past medical history and social history was negative. In physical exam, he was not alert and he had recurrent 
seizures. Blood pressure, heart rate, respiratory rate and temperature were normal. Pupils were mydriatic. Other physical exams were normal. There were not any signs of trauma. He was intubated and admitted in intensive care unit. Antiepileptic agents were prescribed. Urine toxicology test discerned tramadol. Brain computerized tomography scan showed edema and we prescribed mannitol, dexamethasone and depakin consequently. After 5 days his consciousness level improved and after 15 days he was extubated. Finally, he was referred to the ward, but he had bizarre behavior and after some days with the prescription of supportive and rehabilitation measures he was discharged.

\section{Discussion}

Tramadol is an effective analgesic agent for moderate to severe pain with a low level of addiction (15). Tramadol works with two different mechanisms: opioid and nonopioid. These two mechanisms cause good effects and side effect for tramadol (16). One of the most common side effects in overdose or therapeutic dose is seizure (17). Sometimes the frequency of seizures increases, but if seizures are treated as soon as possible, the resultant would be better prognosis (18).

Mortality of status epilepticus is about 7\%-39\% (19), and research shows that opioids like tramadol and morphine can induce status epilepticus (20) (Figure 1). Hypoxicischemic encephalopathy results from some events such as poisoning (drug overdose) (14). There is a great deal of evidence concerning its side effects. Talaie et al in 2009 reported that the prevalence of tramadol seizure is about $46.2 \%$ (12). Mehrpour in 2005 suggested that tramadol can induce status epilepticus (21). The study conducted by Boostani and Derakhshan in 2012 showed that tramadol seizure is generalized tonic-clonic and it happens in 24 hours of tramadol intake, but if tramadol is used with alcohol-antipsychotics-antidepressants, the risk of seizure can be increased (22). A study conducted by Taghaddosinejad et al in 2011 showed that the prevalence

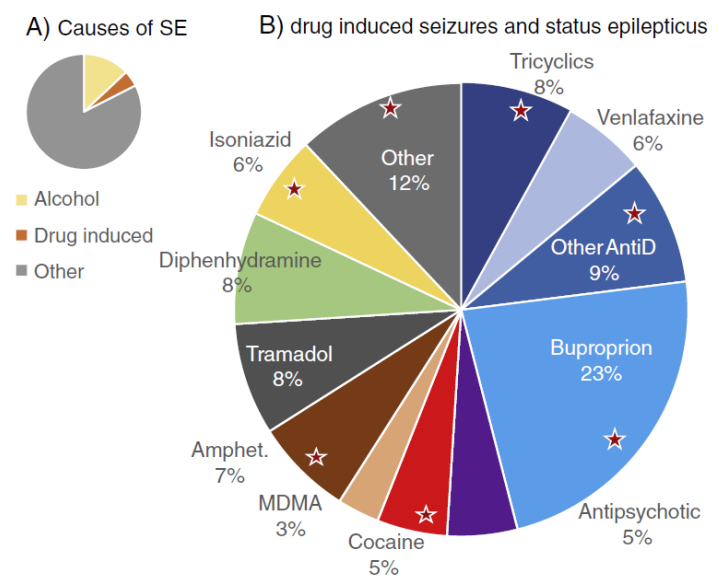

Figure 1. Causes of status epilepticus and drug induced seizures. of tramadol seizure is related to tramadol dose, but it is not related to blood concentration (23). Talaie et al in 2009 indicated that tramadol seizure is not dose dependent (12).

\section{Conclusion}

This study is about one of the most important side effects of tramadol over dose. This study is about one of the most important side effects of tramadol over dose: hypoxicischemic encephalopathy following recurrent seizures induced by Tramadol overdose. He was treated and after some days with the prescription of supportive and rehabilitation measures he was discharged. In recent years the use of tramadol without caution has increased and it is available easily. In this regard, physicians must know how to treat the side effects of this drug.

\section{Authors' contributions}

ZA and BD contributed equally in study design, drafting article, reading critically and accepted finally proof.

\section{Ethical Issues}

Patient's informed consent was obtained regarding the use of personal data for this report.

\section{References}

1. American Pain Society (APS). Principles of Analgesic Use. 7th ed. Chicago, IL: APS; 2016.

2. Grond S, Sablotzki A. Clinical pharmacology of tramadol. Clin Pharmacokinet 2004; 43(13): 879-923. doi: 10.2165/00003088-200443130-00004.

3. Raffa RB, Buschmann $H$, Christoph $T$, Eichenbaum G, Englberger W, Flores CM, et al. Mechanistic and functional differentiation of tapentadol and tramadol. Expert Opin Pharmacother 2012; 13(10): 1437-49. doi: 10.1517/14656566.2012.696097.

4. Fournier JP, Azoulay L, Yin H, Montastruc JL, Suissa S. Tramadol use and the risk of hospitalization for hypoglycemia in patients with noncancer pain. JAMA Intern Med 2015; 175(2): 186-93. doi: 10.1001/ jamainternmed.2014.6512.

5. Shipton EA. Tramadol--present and future. Anaesth Intensive Care 2000; 28(4): 363-74. doi: 10.1177/0310057x0002800403.

6. Gasse C, Derby L, Vasilakis-Scaramozza C, Jick H. Incidence of first-time idiopathic seizures in users of tramadol. Pharmacotherapy 2000; 20(6): 629-34. doi: 10.1592/phco.20.7.629.35174.

7. Rehni AK, Singh I, Kumar M. Tramadol-induced seizurogenic effect: a possible role of opioid-dependent gamma-aminobutyric acid inhibitory pathway. Basic Clin Pharmacol Toxicol 2008; 103(3): 262-6. doi: 10.1111/j.17427843.2008.00276.x.

8. Sun C, Mtchedlishvili Z, Erisir A, Kapur J. Diminished neurosteroid sensitivity of synaptic inhibition and altered location of the alpha4 subunit of GABA(A) receptors in an animal model of epilepsy. J Neurosci 2007; 27(46): 1264150. doi: 10.1523/jneurosci.4141-07.2007. 
9. Wightman RS, Perrone J, Erowid F, Erowid E, Meisel ZF, Nelson LS. Comparative analysis of opioid queries on erowid. org: an opportunity to advance harm reduction. Subst Use Misuse 2017; 52(10): 1315-9. doi: 10.1080/10826084.2016.1276600.

10. Shadnia S, Soltaninejad K, Heydari K, Sasanian G, Abdollahi M. Tramadol intoxication: a review of 114 cases. Hum Exp Toxicol 2008; 27(3): 201-5. doi: 10.1177/0960327108090270.

11. Afshari R, Tashakori A. Tramadol overdose as a cause of serotonin syndrome: a case series. Clin Toxicol 2010; 48(4): 337-41. doi: 10.3109/15563651003709427.

12. Talaie H, Panahandeh R, Fayaznouri MR, Asadi Z, Abdollahi M. Dose-independent occurrence of seizure with tramadol. J Med Toxicol 2009; 5(2): 63-7. doi: 10.1007/BF03161089.

13. Kroenke K, Krebs EE, Bair MJ. Pharmacotherapy of chronic pain: a synthesis of recommendations from systematic reviews. Gen Hosp Psychiatry 2009; 31(3): 206-19. doi: 10.1016/j.genhosppsych.2008.12.006.

14. Wijdicks EF, Hijdra A, Young GB, Bassetti CL, Wiebe S, Quality Standards Subcommittee of the American Academy of Neurology. Practice parameter: prediction of outcome in comatose survivors after cardiopulmonary resuscitation (an evidence-based review): report of the Quality Standards Subcommittee of the American Academy of Neurology. Neurology 2006; 67(2): 203-10. doi: 10.1212/01. wnl.0000227183.21314.cd.

15. Boora K. Tramadol. In: Enna SJ, Bylund DB, eds. xPharm: The Comprehensive Pharmacology Reference. New York:
Elsevier; 2007. p. 1-7. doi: 10.1016/B978-0080552323.62788-6

16. Hoffman RS, Howland MA, Lewin NA, Nelson LS, Goldfrank LR. Goldfrank's Toxicologic Emergencies. 10th ed. US: McGraw-Hill; 2015.

17. Musshoff F, Madea B. Fatality due to ingestion of tramadol alone. Forensic Sci Int 2001; 116(2-3): 197-9. doi: 10.1016/ s0379-0738(00)00374-1.

18. Cock HR. Drug-induced status epilepticus. Epilepsy Behav 2015; 49: 76-82. doi: 10.1016/j.yebeh.2015.04.034.

19. Vignatelli L, Tonon C, D’Alessandro R, Bologna Group for the Study of Status Epilepticus. Incidence and shortterm prognosis of status epilepticus in adults in Bologna, Italy. Epilepsia 2003; 44(7): 964-8. doi: 10.1046/j.15281157.2003.63702.x.

20. Márquez-Romero JM, Zermeño-Pohls F, Soto-Cabrera E. Convulsive status epilepticus associated with a tramadol overdose. Neurologia 2010; 25(9): 583-5. doi: 10.1016/j. nrl.2009.07.001. [In Spanish].

21. Mehrpour M. Intravenous tramadol-induced seizure: two case reports. Iranian Journal of Pharmacology and Therapeutics 2005; 4(2): 146-7.

22. Boostani R, Derakhshan S. Tramadol induced seizure: A 3-year study. Caspian J Intern Med 2012; 3(3): 484-7.

23. Taghaddosinejad F, Mehrpour O, Afshari R, Seghatoleslami A, Abdollahi M, Dart RC. Factors related to seizure in tramadol poisoning and its blood concentration. J Med Toxicol 2011; 7(3): 183-8. doi: 10.1007/s13181-011-0168-0. 